\title{
Médiévales
}

Langues, Textes, Histoire

60 | printemps 2011

La fitna

\section{La fitna : le désordre politique dans l'Islam médiéval}

Gabriel Martinez-Gros et Emmanuelle Tixier du Mesnil

\section{OpenEdition}

1 Journals

Édition électronique

URL : https://journals.openedition.org/medievales/6199

DOI : 10.4000/medievales.6199

ISSN : $1777-5892$

Éditeur

Presses universitaires de Vincennes

Édition imprimée

Date de publication : 30 juin 2011

Pagination : 5-6

ISBN : 978-2-84292-273-3

ISSN : 0751-2708

\section{Référence électronique}

Gabriel Martinez-Gros et Emmanuelle Tixier du Mesnil, « La fitna : le désordre politique dans I'Islam médiéval », Médiévales [En ligne], 60 | printemps 2011, mis en ligne le 19 janvier 2012, consulté le 22 avril 2022. URL : http://journals.openedition.org/medievales/6199; DOI : https://doi.org/10.4000/ medievales.6199 
Médiévales 60, printemps 2011, p. 5-6

\author{
Gabriel MARTINEZ-GROS \\ Emmanuelle TIXIER DU MESNIL
}

\title{
LA FITNA : LE DÉSORDRE POLITIQUE DANS L'ISLAM MÉDIÉVAL
}

Pour la plupart des historiens français, héritiers des révolutions, le désordre est créateur de sens, annonciateur d'un ordre nouveau. Il n'en est pas de même dans l'Islam traditionnel: les chroniqueurs médiévaux tout comme les juristes ou les théologiens ne tiennent pour dignes d'histoire que les règnes glorieux et les sectes victorieuses. Ils rejettent le désordre, la fitna en arabe, dans le nonsens et se refusent même à l'expliquer de peur de le justifier. Selon un célèbre hadith, «mieux vaut soixante ans d'injustice qu'un seul jour de désordre ${ }^{1} »$. À partir de la fin du $\mathrm{XIX}^{\mathrm{e}}$ siècle, les orientalistes, largement prisonniers de leurs sources, ont pérennisé cette approche. Parlant de la fitna andalouse du $\mathrm{XI}^{\mathrm{e}}$ siècle qui met une fin brutale au califat omeyyade de Cordoue, Évariste Lévi-Provençal, grand découvreur et connaisseur des textes de l'Espagne musulmane, la qualifie d'histoire confuse et lamentable, et ce faisant, refuse d'en traiter.

Le contexte de l'hiver 2011 paraît démentir ces vues et remettre en cause ce que Aziz al-Azmeh nomme le «pessimisme anthropologique de l'Islam ${ }^{2} »$, c'està-dire la fondamentale méfiance qu'il convient d'observer envers l'expression désordonnée de la liberté, et la conviction que le frein et la contrainte sont nécessaires à l'équilibre des sociétés. Il nous semble donc opportun de présenter

1. L'horreur du désordre et la recherche du consensus, chez les hommes de religion sunnites en particulier, prennent probablement leur source dans les plaies jamais refermées de la grande fitna, c'est-à-dire la guerre civile qui opposa Alî et Mu'awiya à la fin de la première génération de l'Islam (656-661), cf. H. Duaït, La Grande Discorde, Paris, 1990.

2. A. Al-Azmen, Power and the Sacred in Muslim, Christian and Pagan Polities, Londres, 2001. 
aujourd'hui ce dossier sur la fitna et le désordre dans l'Islam médiéval, et ce d'autant plus que l'historiographie en est singulièrement pauvre ${ }^{3}$.

Spécialistes de l'Espagne musulmane, nous avons privilégié la part occidentale du monde islamique, d'al-Andalus au Maghreb et à la Sicile, entre le $\mathrm{IX}^{\mathrm{e}}$ et le XII ${ }^{\mathrm{e}}$ siècle.

Nous avons choisi d'ouvrir ce dossier avec le fameux historien du XIV $V^{e}$ siècle Ibn Khaldûn: l'analyse des occurrences du mot fitna dans sa grande chronique universelle, le Kitâb al-'Ibar, offre une grille de lecture générale du concept (Gabriel Martinez-Gros). Dans l'Islam occidental, ce sont les troubles que déchaîne la chute du califat omeyyade (1009-1031) qui ont mérité par excellence le nom de fitna. Trois contributions s'attachent à les analyser: Emmanuelle Tixier du Mesnil présente la complexité événementielle et les enjeux longtemps tenus pour ethniques d'une histoire fondamentalement politique. Sophie Makariou exhume un meurtre d'État dont la mémoire anime encore, une génération plus tard, les premiers acteurs de la fitna. Spécialiste de la littérature arabe andalouse, Brigitte Foulon évoque l'existence douloureuse de quelques grandes figures de poètes pris dans la tourmente et l'exil de la fitna. Cyrille Aillet rappelle cependant qu'un précédent temps des troubles avait traversé l'histoire omeyyade à la fin du $\mathrm{IX}^{\mathrm{e}}$ siècle; et il interroge une interprétation elle aussi restée longtemps ethnique. Dans l'Espagne musulmane du XII siècle, Yann Dejugnat explore la riche polysémie du terme en mettant en lumière les racines politiques de l'épreuve spirituelle (fitna) du mystique Abû Bakr Ibn al- 'Arabî. Par comparaison, la Sicile, étudiée par Annliese Nef, n'offre guère d'exemple abouti et documenté de fitna. Spécialistes de l'Islam, nous avons enfin trouvé notre exotisme dans l'analyse de l'Occident chrétien du XIII' siècle. Là où l'historiographie traditionnelle voyait le temps de l'ordre et de l'équilibre des royautés féodales, Gilles Lecuppre repère les symptômes d'un désordre organique. Les deux mondes en ressortent plus proches dans leur complexité.

Gabriel Martinez-Gros - Université de Paris Ouest-Nanterre La Défense, EA 1587, Département d'histoire, 200 avenue de la République, F-92001 Nanterre cedex

Emmanuelle Tixier du Mesnil - Université de Paris Ouest-Nanterre La Défense, EA 1587, Département d'histoire, 200 avenue de la République, F-92001 Nanterre cedex

3. Même dans les années soixante et soixante-dix, dans le contexte de la décolonisation et d'une historiographie marxisante, révoltes et révolutions dans l'Islam médiéval n'ont guerre suscité de travaux fondamentaux, à l'exception de l'ouvrage d'Alexandre Popovic (La Révolte des esclaves en Iraq au III $/ I^{e}$ s., Paris, 1976) sur la révolte des esclaves africains du sud de l'Iraq soulevés contre le califat abbasside à la fin du $\mathrm{IX}^{\mathrm{e}}$ siècle. 